\title{
Competências Empreendedoras de Dirigentes de Empresas Brasileiras de Médio e Grande Porte que Atuam em Serviços da Nova Economia
}

\author{
Sérgio Carvalho Benício de Mello \\ André Luiz Maranhão de Souza Leão \\ Fernando Gomes de Paiva Júnior
}

\section{ResUMo}

Num contexto de estímulo ao empreendedorismo, uma compreensão de comportamentos relacionados a competências empreendedoras é crítica. Tal perspectiva apresenta valiosas contribuições para o desenvolvimento e a gestão de negócios, bem como para a interação com grupos internos e externos da organização. Neste sentido, competência pode ser entendida como um construto que engloba diferentes traços de personalidade, habilidades e conhecimentos. Este estudo corresponde a uma pesquisa qualitativa, realizada por meio de análise de conteúdo clássica, junto a dirigentes de empresas brasileiras da nova economia, sediadas no eixo Rio-São Paulo. Os resultados demonstraram uma prevalência das competências conceituais e administrativas. Além disto, uma competência não prevista na literatura - equilíbrio entre trabalho e vida pessoal - foi descoberta. Conclusões e implicações gerenciais são também discutidas.

Palavras-chave: competências empreendedoras; comportamento empreendedor; negócios da nova economia.

\begin{abstract}
In a context where entrepreneurship is being stimulated, an understanding of behavior related to entrepreneur competences is critical. Such perspective presents a valuable contribution to business development and management, as well as for external and internal organization group interaction. Thus, competence may be understood as a construct that includes different personality traits, skills and knowledge. This study has a qualitative research approach. A series of interviews with new economy Brazilian C.E.O.s, based in Rio de Janeiro and São Paulo was undertaken, followed by a content analysis. Results indicate conceptual and managerial competences prevalence. Besides, a competence not indicated in the literature - work-life balance competence - was discovered. Conclusions and managerial implications are also discussed.
\end{abstract}

Key words: entrepreneur competences; entrepreneur behavior; new economy businesses. 


\section{INTRODUÇÃO}

No contexto da nova economia, as relações de mercado permeiam as práticas empreendedoras de forma complexa e confusa (independentemente das localidades nacionais ou regionais); os recursos que guiam as atividades imateriais, ligados ao tecido humano e ao social; e a qualidade das competências (Benko, 2002). Nessa ótica, a sociedade pós-capitalista, concebida como do conhecimento, demanda um indivíduo universalmente instruído, cujas características se concentram em absorver o conhecimento e a sabedoria herdados da tradição humana, em paralelo com a ciência do presente e a moldagem do futuro (Drucker, 2002). Essa pessoa terá que ser preparada para enfrentar o mundo globalizado e informacional, ato que requer tanto o saber fazer, como o saber ser. Tais imperativos são determinantes de sobrevivência, contextualizada no aprender a aprender, e podem ser traduzidos na prática de geração do crescimento organizacional por meio de mecanismos recursivos de formação de competências (Demo, 1994).

No campo dos estudos organizacionais, incluindo treinamento e desenvolvimento vocacional, tem havido, em âmbito mundial, ênfase na necessidade de se aperfeiçoarem habilidades e capacidades que gerem reflexões sobre as práticas profissionais. A crítica mais comum para tal preocupação parece residir na necessidade de suporte para dirigentes e equipes enfrentarem, de forma efetiva, as crescentes mudanças sociais, em particular aquelas que contribuem para incrementar a incerteza nos negócios e, conseqüentemente, no mercado de trabalho (Gibb, 1999; Schön, 1991).

Existem competências associadas a posturas empreendedoras que auxiliam na compreensão de atributos geradores de respostas de valor na interação com grupos internos e externos da organização. Elas se vinculam ao senso de identificação de oportunidades, à capacidade de relacionamento em rede, às habilidades conceituais, à capacidade de gestão, à facilidade de leitura, ao posicionamento em cenários conjunturais e ao comprometimento com interesses individuais e da organização. Esses elementos são básicos no desenvolvimento de artefatos representativos, como expressão de crescimento pessoal e profissional do dirigente de êxito (Birley \& Muzuka, 2001; Man \& Lau, 2000; Man, Lau, \& Chan, 2002; Pinto, 2000).

Deste modo, surge uma pergunta que representa o foco deste estudo: que áreas de competências empreendedoras são mais relevantes nos comportamentos de 
dirigentes de perfil empreendedor? Com base nisto, torna-se necessária uma pergunta complementar: que comportamentos específicos compõem as áreas de competências?

\section{Referencial Teórico}

Competência pode ser concebida como característica que engloba diferentes traços de personalidade, habilidades e conhecimento, influenciados pela experiência, capacitação, educação, história familiar e aspectos demográficos peculiares à pessoa (Kets De Vries, 1996; Man \& Lau, 2000).

Fraser (2000) assinala a ênfase que a literatura confere a padrões comportamentais concebidos como diferenciados, ao sugerir que empresas em fase de crescimento devem fomentar estilos de organizações flexíveis e generalistas, eliminar excessos burocráticos, intensificar discussões informais e explorar recursos gerados por terceiros num clima de reciprocidade de negócios em rede. No entanto não adianta estabelecer padrões criativos e empreendedores no plano abstrato das organizações, sem conceber que a versatilidade das estruturas estratégicas advém de ações de indivíduos que movimentam posturas adquiridas ao longo da trajetória pessoal e profissional (Enriquez, 1997).

O estudo realizado por Storey (2002) junto a dirigentes de médias empresas do Reino Unido constata que as atitudes e práticas voltadas para a educação, treinamento e desenvolvimento, numa concepção mais ampla de aprendizagem, demonstram correlação com a melhoria do desempenho organizacional. Em meio a outros fatores internos e externos que afetam o desempenho da empresa, cabe destacar o dirigente de perfil empreendedor como ser que vincula a competitividade empresarial com a abordagem da competência no estrato da ação humana, tanto numa perspectiva de processo quanto sob a égide comportamental (Man et al., 2002).

Ao pressupor que as competências são demonstradas por comportamentos observáveis condicionantes da capacidade pessoal de realizar ações estratégicas de expansão empresarial, elas constituem o foco de reflexão deste estudo. Com base nos estudos de Man e Lau (2000), as competências serão categorizadas em seis áreas distintas de comportamento, quais sejam: a competência de oportunidade, de relacionamento, conceituais, administrativas, estratégicas e de comprometimento. Além disto, também uma revisão acerca da competência de equilíbrio trabalho/vida pessoal foi realizada, tendo em vista que, como será exposto nos resultados da pesquisa, esta categoria emergiu na análise dos dados deste estudo. 


\section{Competências de Oportunidade}

O reconhecimento de oportunidades de negócios pode ser amplamente dividido em três conglomerados: identificação, avaliação e busca de oportunidade de mercado. Tais aglomerados sugerem que um empreendedor deve estar apto a identificar os cenários favoráveis aos objetivos organizacionais e atuar sobre as chances potenciais de negócios por meio da sua avaliação, de modo a transformálas em situações positivas.

A ação empreendedora de reconhecimento de oportunidades de negócios, definida por Hills e Laforge (1996) como sendo a percepção de potencial para novos lucros por meio da fundação e aperfeiçoamento de empreendimentos ou da melhoria significativa de um negócio já existente, faculta seu avanço ao estabelecimento de estruturas que garantam desempenhos satisfatórios ao longo da vida efetiva da empresa.

Essa competência requer elementos de preparação da empresa, uma vez que existe convergência de fatores controláveis, como a vigilância, seleção da equipe de trabalho, estudos, risco de uma nova atividade e mudança de estilo de vida, além das não controláveis, a exemplo dos aspectos culturais, sociais e econômicos, que afetam a habilidade de um potencial empreendedor no sentido de reconhecer a tal oportunidade (Stevenson \& Gumpert, 1985).

\section{Competências de Relacionamento}

A atração de novos recursos demanda do empreendedor a capacidade de criação e fortalecimento de uma imagem de confiança, boa reputação, capacidades no setor, compromisso e conduta junto a redes de relacionamentos com parceiros efetivos e potenciais (Ring \& Van De Ven, 1994; Brush, Greene, \& Hart, 2002).

A preocupação com o relacionamento em rede (networking), reconhecido como fundamental para o desenvolvimento profissional, expande-se gradativamente para o cotidiano das pessoas como prática inexorável de sobrevivência num saberfazer relacional (netliving) (Minarelli, 2001). Ao discutir a modalidade inovadora das empresas japonesas no pós-fordismo, Coriat (1994) já alertava que a competência relacional acrescentava inovações nos relacionamentos entre firmas por meio do intercâmbio de produtos e conhecimentos disponíveis e necessários à reprodução dos seus resultados.

Os envolvimentos estratégicos aprimoram o desempenho inovador na medida em que a pesquisa de mercado e as atividades de pesquisa e desenvolvimento são aperfeiçoadas pelas informações compartilhadas na rede (Castells, 1999). 
Esse processo é tarefa dos indivíduos em posição estratégica na organização, na medida em que os dirigentes devem conduzir e ir adaptando conceitualmente os objetivos e recursos com base nas oportunidades que emergem no ambiente (Keegan, 1995).

\section{Competências Conceituais}

Ao ponderar que os empreendedores são hábeis observadores, tanto das oportunidades do ambiente externo quanto dos aspectos internos da organização, cabe reconhecer que eles driblam etapas normais do processo decisório e desenvolvem ações velozes e intuitivas (Man \& Lau, 2001). Paralelamente, são capazes de perceber situações por ângulos diferentes ou de forma positiva, de modo a encontrar alternativas para a mesma questão: quando as outras pessoas estão vendo o mercado saturado, esses indivíduos podem descobrir nichos para penetrar nesse mercado e se adaptar a novas situações, não apenas relacionadas a novos produtos e tecnologias, como também à reformulação dos produtos e serviços já existentes ou à penetração em outros mercados (Man et al., 2000). Um empreendedor eficiente dever ter capacidade de avaliar situações de risco que surgem em decorrência de suas ações em qualquer dos ambientes.

\section{Competências Administrativas}

A competência administrativa se refere à eficiente alocação de talentos, recursos físicos, financeiros e tecnológicos. Esse processo se desdobra em mecanismos de planejamento, organização, comando, motivação, delegação e controle (Man \& Lau, 2000). Deste modo, quando os recursos como fundos, parcerias e empregados não estão disponíveis na empresa, os empreendedores necessitam captá-los no ambiente de negócio de modo a fortalecer as potencialidades de sua empresa. A questão básica com respeito aos recursos, que Birley e Muzuka (2000) assinalam, correspondem aos elementos necessários aos múltiplos estágios de desenvolvimento da empresa. Assim, o empreendedor tenta maximizar a criação de valor, minimizando o conjunto de recursos disponíveis, o que implica aceitação de maiores riscos.

Em situações de crise, uma organização reconhecida como madura também adota uma configuração de empresa empreendedora, quando lança mão de uma liderança criativa e relacional que imprima uma visão integrada e seu controle personalizado para motivar as pessoas a terem alto desempenho (Dollinger,1995; Gibb, 1999; Mintzberg, Ahlstrand, \& Lampel, 2000; Mintzberg \& Quinn, 2001). 


\section{Competências Estratégicas}

As competências relacionadas à escolha e implementação das estratégias da empresa constituem uma área especial de comportamento empreendedor. Os empreendedores eficazes tanto visualizam panoramas de longo prazo como também planejam objetivos e posicionamentos de médio prazo alcançáveis e realistas. Eles devem estar aptos a perceber tendências emergentes no ambiente, sintonizarse com informações diversas e conseguir ajustar suas percepções na direção das forças ambientais (Mintzberg et al., 2001). Esses indivíduos têm de ser mais hábeis do que os demais membros da organização na tarefa de gerenciar sua complexidade (Kets De Vries, 1997).

Mudanças estratégicas são necessárias para encarar as transformações ambientais, ou para adotar táticas para enfrentar os clientes e os concorrentes. Eles também são responsáveis por estimação da viabilidade financeira de mecanismos de controle dos seus resultados.

O método de direcionamento estratégico aumenta a confiança do dirigente, quanto ao rumo que está seguindo e proporciona orientação importante para a equipe, ao apresentar imagem de profissionalismo junto aos clientes (Kerns, 2002).

\section{Competências de Comprometimento}

As competências de comprometimento são as que demandam a habilidade de manter a dedicação do dirigente ao negócio, sobretudo em situações adversas. Tal compromisso pode também ser ilustrado pela devoção ao trabalho árduo e pelo desejo de alcançar objetivos de longo prazo em detrimento dos ganhos de curto prazo. Ao lado disso, deve haver a capacidade de recomeçar a atividade empresarial, mesmo após situações de insucesso, ou a disposição de não abandonar o negócio no seu período de crescimento, mesmo na ocorrência de crises setoriais (Man \& Lau, 2000).

Muitas vezes a dedicação à atividade empresarial vincula-se a outras motivações, tais como o senso de responsabilidade com respeito à equipe ou mesmo à manutenção de crenças e valores pessoais. Os valores e os objetivos relacionam-se ao esforço de empreendimento ocorrido no passado, a aspirações de avanços no setor de atividade, a um senso de auto-reciclagem gerador de capacidade de crescimento e à força para trabalhar continuamente em meio das dificuldades enfrentadas.

\section{Competências de Equilíbrio entre Trabalho e Vida Pessoal}

O estudo realizado por Friedman, Christesen e Degroot (1998) constata que 
um crescente número de dirigentes atuam sob o pressuposto do equilíbrio entre o trabalho e a vida pessoal. Eles declaram que tais instâncias são complementares, e não concorrentes, em termos de prioridades. Esta postura é reconhecida pelos autores como filosofia ganha-ganha, repercutindo-se tanto na organização como na vida pessoal dos seus colaboradores. Tais dirigentes são orientados por princípios que repercutem num círculo virtuoso para a empresa, como esclarecer o que é importante, reconhecer a equipe e dar-lhe apoio como seres humanos plenos e assumir ou mesmo prestigiar o fato de que existem papéis a serem cumpridos fora do espaço de trabalho.

\section{Procedimentos Metodológicos e Analíticos}

Este estudo corresponde a uma pesquisa de natureza qualitativa. A coleta dos dados consistiu em sete entrevistas semi-estruturadas e em profundidade, realizadas com dirigentes de empresas brasileiras de médio e grande porte, que atuam em serviços da nova economia, sediadas no eixo Rio-São Paulo. A escolha dos empreendedores se deu por meio de uma pesquisa exploratória de dados secundários, na qual se levantaram aqueles de maior notoriedade na direção de serviços da nova economia. Num segundo momento, estes foram contatados via e-mail e os sete empreendedores da amostra se referem àqueles que concordaram em participar do estudo. Não foram selecionadas empresas, portanto, mas empreendedores. As empresas empreendedidas por estes sete sujeitos incluem provedores de acesso à Internet, sites de comércio eletrônico, de mecanismo de busca na Internet, produtora multimídia etc.

As entrevistas foram realizadas também por meio de troca de e-mails, tendo sido pautadas em um protocolo que partia de três perguntas iniciais, levantando o que é ser empreendededor para o entrevistado; se foi um sonho ou um ideal que o transformou em empreendedor; e como foi para ele/ela abrir a (primeira, se fosse o caso) empresa. A partir daí, as questões se adaptavam às respostas, mas sempre tendo em perspectiva aspectos de ordem profissional e pessoal dos empreendedores.

O plano analítico compreendeu uma análise de conteúdo com processo de transcrição dos relatos dos entrevistados, codificação dos conteúdos e interpretação de seus significados (Bauer \& Gaskell, 2002). Tal metodologia é compreendida como um conjunto de técnicas de análise das comunicações, focada numa investigação por meio de uma descrição objetiva, sistemática e quantitativa do conteúdo manifesto, com a finalidade da interpretação da mensagem (Bardin, 1977). 
As categorias de análise foram definidas com base nas seis áreas de competências propostas por Man e Lau (2000), conforme antecipado no referencial teórico. Entretanto algumas competências foram percebidas como conceitualmente superpostas, suscitando a necessidade de alterações de ordem contextual e conceitual. Algumas competências apresentadas pelos autores foram reclassificadas, todas como administrativas (Gerenciar conflitos entre os empregados; Promover o consenso entre os parceiros no processo de tomada de decisão; Comunicar-se eficazmente interna e externamente; Expor-se com habilidade junto à mídia, previstas como de relacionamento; Utilizar recursos e capacidades que gerem resultados, prevista como uma competência estratégica). Depois, novas configurações precisaram ser realizadas, chegando-se, em alguns casos, a um terceiro nível de códigos. Dentre as competências de relacionamento, duas referentes a construir e manter redes de relacionamento e credibilidade e confiança com clientes internos e externos, efetivos e potenciais, foram sintetizadas em uma: Construir e manter redes de relacionamentos com stakeholders. Outras duas, referentes à utilização destas redes de relacionamento e credibilidade e confiança, foram sintetizadas em outra: Construir e manter credibilidade e confiança com clientes internos e externos que, agrupada com Negociar com os parceiros de negócios, formou a nova categoria: Utilizar-se dos relacionamentos. Dentre as competências conceituais, uma categoria intitulada Racionar de forma criativa agrupou Pensar intuitivamente e Ver por um ângulo diferente e outra, intitulada Lidar com o risco incluiu Avaliar riscos (prevista pelo autor), além de uma nova, descoberta na análise. No que concerne às competências administrativas, ocorreram as maiores alterações: Organizar e Liderar (previstas pelo autor) se transformaram em grupos de competências. A primeira agregou a competência mencionada, prevista como estratégica, enquanto a segunda agregou duas das competências descritas como de relacionamento (Gerenciar conflitos entre os empregados, Promover o consenso entre os parceiros no processo de tomada de decisão), além de motivar e delegar, apresentadas pelos autores num mesmo nível hierárquico. As outras duas competências propostas como de relacionamento foram agrupadas como Atuar mercadologicamente. Finalmente, quanto às competências estratégicas e as de comprometimento, foram mantidas as mesmas (à exceção da estratégica classificada como administrativa), porém agrupadas de forma mais concisa, em três e duas categorias, respectivamente.

Baseado nisto, um mapa de codificação foi gerado. A partir daí, entrevistas começaram a ser analisadas e cada trecho representativo de competências recebeu um código de acordo com a adequação à determinada categoria (podendo uma frase obter mais de um código). Os dados foram codificados na medida em que foram coletados, como recomendam Miles e Huberman (1994), já que postergar a codificação para quando todos os dados estiverem coletados significa empobrecer a análise, além de tornar o próprio processo de codificação muito cansativo. 
Caso um trecho representativo não se adequasse a nenhuma categoria, foi classificado como não categorizado, para, posteriormente, ser analisado. Tais novos códigos foram, em sua maioria, ajustados às seis dimensões previstas Identificar sinergia com parceiros (competência de oportunidade); Recorrer às relações pessoais (competência de relacionamento, da subcategoria Utilizar-se dos relacionamentos); Ter vocação, Ter autonomia, Ter sensibilidade e vontade de aprender e Assumir riscos (competências conceituais, sendo a última da subcategoria Lidar com riscos); Atender de pronto ao cliente, Ser ágil em tomada de decisão, Vender eficazmente e Atribuir valor ao seu produto/negócio (competências administrativas, sendo as duas primeiras da subcategoria Organizar e as outras duas da subcategoria Atuar mercadologicamente); Ter intencionalidade para a ação, Estabelecer o posicionamento, Gerar uma identidade corporativa a partir de suas características e Ter agressividade competitiva (competências estratégicas) - e dois deles (Dar vazão ao estresse e Ter uma compreensão lúdica/prazerosa do trabalho) compuseram uma nova categoria, denominada Competências de equilíbrio trabalho/vida pessoal, conforme antecipado. O mapa de codificação completo é apresentado na Tabela 1.

\section{Tabela 1: Áreas de Competências e Definições dos Comportamentos}

\begin{tabular}{|c|c|c|}
\hline Cód. & Dimensões da competência & Definições \\
\hline 10 & \multicolumn{2}{|l|}{ Oportunidade } \\
\hline 101 & $\begin{array}{l}\text { Identificar as oportunidades de negócios } \\
\text { a partir de experiências prévias }\end{array}$ & $\begin{array}{l}\text { Identificar lacunas de mercado não atendidas, por meio de } \\
\text { relacionamentos, operações de negócios e mudanças } \\
\text { ambientais. }\end{array}$ \\
\hline 102 & $\begin{array}{l}\text { Avaliar os espaços de mercado não } \\
\text { atendidos }\end{array}$ & $\begin{array}{l}\text { Avaliar tendências e mudanças de mercado e da } \\
\text { concorrência. }\end{array}$ \\
\hline 103 & $\begin{array}{l}\text { Pesquisar oportunidades por meio dos } \\
\text { esforços de marketing }\end{array}$ & $\begin{array}{l}\text { Desenvolver pesquisas de mercado e sistemas de } \\
\text { inteligência de marketing para detectar oportunidades. }\end{array}$ \\
\hline 104 & Identificar sinergia com parceiros & Identificar otimização de esforços com parceiros. \\
\hline 11 & \multicolumn{2}{|l|}{ Relacionamento } \\
\hline 111 & $\begin{array}{l}\text { Construir e manter redes de } \\
\text { relacionamentos com stakeholders }\end{array}$ & $\begin{array}{l}\text { Construir e manter relacionamentos de confiança e } \\
\text { credibilidade junto a clientes, fornecedores, } \\
\text { intermediários, colaboradores internos e acionistas. }\end{array}$ \\
\hline 112 & Utilizar-se dos relacionamentos & \\
\hline 1121 & $\begin{array}{l}\text { Utilizar-se das redes de } \\
\text { relacionamentos construídas com } \\
\text { stakeholders }\end{array}$ & $\begin{array}{l}\text { Utilizar-se das redes para adquirir e fortalecer as } \\
\text { oportunidades e para obter recursos e capacidades. }\end{array}$ \\
\hline 1122 & $\begin{array}{l}\text { Negociar com os parceiros de } \\
\text { negócios }\end{array}$ & $\begin{array}{l}\text { Jogar de forma "ganha-ganha" para fortalecer a confiança } \\
\text { e credibilidade na rede. }\end{array}$ \\
\hline 1123 & Recorrer às relações pessoais & $\begin{array}{l}\text { Recorrer a pessoas e grupos de referencia oriundos do } \\
\text { cotidiano secular a favor da prática profissional. }\end{array}$ \\
\hline 12 & Competências conceituais & \\
\hline 121 & Raciocinar de forma criativa & \\
\hline 1211 & Pensar intuitivamente & Observar, analisar e avaliar de forma subjetiva. \\
\hline 1212 & Ver por um ângulo diferente & $\begin{array}{l}\text { Analisar os caminhos alternativos e alcançar melhores } \\
\text { soluções. }\end{array}$ \\
\hline 122 & Inovar & Diferenciar-se em mercados, produtos e tecnologias. \\
\hline 123 & Lidar com o risco & \\
\hline 1231 & Avaliar riscos & Avaliar situações duvidosas. \\
\hline 1232 & Assumir riscos & Tomar decisão em situação de incerteza. \\
\hline
\end{tabular}




\section{(continuação)}

\section{Tabela 1: Áreas de Competências e Definições dos Comportamentos}

\begin{tabular}{|c|c|c|}
\hline Cód. & Dimensões da competência & Definições \\
\hline 12 & \multicolumn{2}{|l|}{ Competências conceituais } \\
\hline 124 & Ter vocação & Demonstrar talento empreendedor. \\
\hline 125 & Ter autonomia & Agir de forma livre de modo a manter o autocontrole. \\
\hline 126 & Ter sensibilidade e vontade de aprender & Teorizar a prática cotidiana. \\
\hline 13 & \multicolumn{2}{|l|}{ Competências administrativas } \\
\hline 131 & Planejar & Elaborar ordenadamente as ações futuras \\
\hline 132 & Organizar & \\
\hline 1321 & Alocar recursos eficientemente & Distribuir os recursos de forma racional e criativa. \\
\hline 1322 & $\begin{array}{l}\text { Utilizar recursos e capacidades que } \\
\text { gerem resultados }\end{array}$ & $\begin{array}{l}\text { Alcançar eficácia satisfatória com os recursos e } \\
\text { capacidades disponíveis. }\end{array}$ \\
\hline 1323 & Atender de pronto ao cliente & Diligência na satisfação de necessidades do cliente. \\
\hline 1324 & Ser ágil em tomada de decisão & Tomar decisões rápidas e criativas. \\
\hline 133 & Liderar & \\
\hline 1331 & Ter liderança sobre a equipe & Conduzir os colaboradores internos. \\
\hline 1332 & $\begin{array}{l}\text { Gerenciar conflitos entre os } \\
\text { empregados }\end{array}$ & Alinhar interesses funcionais antagônicos. \\
\hline 1333 & $\begin{array}{l}\text { Promover o consenso entre os } \\
\text { parceiros no processo de tomada de } \\
\text { decisão }\end{array}$ & $\begin{array}{l}\text { Orquestrar a atuação dos parceiros conforme os objetivos } \\
\text { estratégicos }\end{array}$ \\
\hline 1334 & Motivar a equipe & $\begin{array}{l}\text { Gerar estímulos que dinamizem o empenho dos talentos } \\
\text { internos. }\end{array}$ \\
\hline 1335 & Delegar tarefas & $\begin{array}{l}\text { Descentralizar e monitorar responsabilidades para } \\
\text { colaboradores capacitados. }\end{array}$ \\
\hline 134 & Controlar & $\begin{array}{l}\text { Normatizar, estabelecer recompensas e sanções e } \\
\text { monitorar as desviações. }\end{array}$ \\
\hline 135 & Atuar mercadologicamente & \\
\hline 1351 & $\begin{array}{l}\text { Comunicar-se eficazmente interna e } \\
\text { externamente }\end{array}$ & Transmitir mensagens curtas e informativas. \\
\hline 1352 & $\begin{array}{l}\text { Expor-se com habilidade junto à } \\
\text { mídia }\end{array}$ & $\begin{array}{l}\text { Incrementar a imagem publicitária da empresa sem ônus } \\
\text { financeiro. }\end{array}$ \\
\hline 1353 & Vender eficazmente & $\begin{array}{l}\text { Alcançar receitas financeiras por meio da comercialização } \\
\text { dos serviços. }\end{array}$ \\
\hline 1354 & Atribuir valor ao seu produto/negócio & Avaliar os atributos do produto de forma eficiente. \\
\hline 14 & Competências estratégicas & \\
\hline 141 & Planejar estrategicamente & \\
\hline 1411 & Ter visão abrangente & Ter compreensão de cenários ampla e de longo prazo. \\
\hline 1412 & Estabelecer e avaliar objetivos & Estabelecer objetivos realísticos e viáveis. \\
\hline 1413 & Ter intencionalidade para a ação & Predisposição para atuação empreendedora. \\
\hline 142 & $\begin{array}{l}\text { Posicionar o produto/negócio no } \\
\text { mercado }\end{array}$ & \\
\hline 1421 & Definir e avaliar posicionamento & $\begin{array}{l}\text { Identificar e avaliar a posição competitiva da imagem de } \\
\text { marca junto ao público-alvo. }\end{array}$ \\
\hline 1422 & Estabelecer o posicionamento & Saber adequar estratégias de posicionamento adequadas. \\
\hline 1423 & $\begin{array}{l}\text { Gerar uma identidade corporativa a } \\
\text { partir de suas características }\end{array}$ & $\begin{array}{l}\text { Desenvolver estratégias de identidade corporativa com } \\
\text { base nos valores e crenças pessoais. }\end{array}$ \\
\hline 1424 & Ter agressividade competitiva & Viabilizar posição vantajosa da empresa frente aos rivais. \\
\hline 143 & Gerir estrategicamente & \\
\hline 1431 & $\begin{array}{l}\text { Realizar mudanças estratégicas em } \\
\text { ambientes adversos }\end{array}$ & $\begin{array}{l}\text { Gerar respostas estratégicas a mudanças ambientais e } \\
\text { condições hostis de mercado. }\end{array}$ \\
\hline 1432 & Executar metas estabelecidas & $\begin{array}{l}\text { Capacidade de implementar ações programadas e não- } \\
\text { programadas em função das metas. }\end{array}$ \\
\hline 1433 & Utilizar táticas & Usar táticas frente a clientes e concorrentes. \\
\hline
\end{tabular}




\section{(conclusão)}

\section{Tabela 1: Áreas de Competências e Definições dos Comportamentos}

\begin{tabular}{|c|c|c|}
\hline Cód. & Dimensões da competência & Definições \\
\hline 14 & \multicolumn{2}{|l|}{ Competências estratégicas } \\
\hline 1434 & Orçar a implementação da estratégia & $\begin{array}{l}\text { Estimar a viabilidade financeira da implementação da } \\
\text { estratégia. }\end{array}$ \\
\hline 1435 & Controlar os resultados das estratégias & Monitorar os resultados da implementação da estratégia. \\
\hline 15 & Competências de comprometimento & \\
\hline 151 & Comprometimento com o negócio & \\
\hline 1511 & $\begin{array}{l}\text { Manter o comprometimento em } \\
\text { relação ao negócio }\end{array}$ & $\begin{array}{l}\text { Manter o compromisso com o negócio mesmo em } \\
\text { situações de crise. }\end{array}$ \\
\hline 1512 & $\begin{array}{l}\text { Comprometer-se com os objetivos de } \\
\text { longo prazo }\end{array}$ & $\begin{array}{l}\text { Manter o compromisso com objetivos de longo prazo } \\
\text { mais que com os de curto prazo. }\end{array}$ \\
\hline 1513 & Dedicar-se ao trabalho & Trabalhar arduamente pela empresa. \\
\hline 1514 & Comprometer-se com a equipe & Ser responsável pela atuação dos empregados. \\
\hline 152 & Comprometimento pessoal. & \\
\hline 1521 & $\begin{array}{l}\text { Comprometer-se com suas crenças e } \\
\text { valores }\end{array}$ & $\begin{array}{l}\text { Comprometer-se com o cumprimento de ações } \\
\text { compatíveis com as crenças e valores pessoais. }\end{array}$ \\
\hline 1522 & $\begin{array}{l}\text { Comprometer-se com objetivos } \\
\text { pessoais. }\end{array}$ & $\begin{array}{l}\text { Comprometer-se com os próprios interesses em termos de } \\
\text { vida pessoal. }\end{array}$ \\
\hline 1523 & Recomeçar após fracassos & $\begin{array}{l}\text { Disposição para reiniciar a atividade mesmo após } \\
\text { situações de insucesso. }\end{array}$ \\
\hline 16 & \multicolumn{2}{|c|}{ Competências de equilíbrio trabalho/vida pessoal } \\
\hline 161 & Dar vazão ao estresse & Desenvolver atividades alheias ao cotidiano da empresa. \\
\hline 162 & $\begin{array}{l}\text { Ter uma compreensão lúdica/prazerosa } \\
\text { do trabalho }\end{array}$ & $\begin{array}{l}\text { Compreender a rotina das atividades de forma bem } \\
\text { humorada e como sendo um jogo desafiante. }\end{array}$ \\
\hline
\end{tabular}

Após a codificação e ordenação de todos os dados, foi realizada uma análise de frequiência representativa do número de vezes que determinado código foi mencionado nas entrevistas. As tabelas de freqüência que serão apresentadas na análise dos resultados incluem menções extraídas das entrevistas, de acordo com o aparecimento e relevância, num total de 326 citações.

\section{Apresentação dos Resultados}

Os resultados serão apresentados visando substanciar as respostas para as perguntas de pesquisa. Inicialmente, uma visão geral dos resultados de todas as áreas de competências e, em seguida, uma análise de cada umas das áreas.

\section{Áreas de Competências}

Conforme a Tabela 2 evidencia, a área de competência que emerge como mais importante é a conceitual, reforçando a idéia de ação criativa e ágil, marcada pela subjetividade do empreendedor, além de sua propensão a atuar em situações de risco como definidores da postura empreendedora (Kuratko \& Hodgetts, 1995; 
Man \& Lau, 2000). Também a área de competências administrativas apresentou uma relevante participação na amostra, fato que demonstra a necessidade de maior inserção de conhecimentos gerenciais na prática de geração e crescimento de negócio, concebido por Gibb (1999) como processo gerencial necessário ao empreendedor para o enfrentamento das incertezas ambientais. As competências estratégicas e de comprometimento aparecem nos conteúdos com freqüências relativamente homogêneas, significando a preocupação do dirigente no sentido de gerar o negócio e mantê-lo vivo e crescente com cuidados semelhantes. Já a capacidade de equilíbrio entre as atividades do trabalho e a vida pessoal constitui a descoberta desta pesquisa, por ser uma área não antecipada, fator que demonstra coma as questões psicológicas e sociais do empreendedor têm repercussão positiva na vitalidade da organização (Boyd \& Gumpert, 1983; Friedman et al., 1998).

\section{Tabela 2: Incidência das Áreas de Competência}

\begin{tabular}{|c|l|c|c|}
\hline Código & Classificação & Freq. & $\mathbf{\%}$ \\
\hline 10 & Competências de oportunidade & 31 & 8,1 \\
\hline 11 & Competências de relacionamento & 21 & 5,5 \\
\hline 12 & Competências conceituais & 101 & 26,4 \\
\hline 13 & Competências administrativas & 91 & 23,8 \\
\hline 14 & Competências estratégicas & 61 & 15,9 \\
\hline 15 & Competências de comprometimento & 66 & 17,2 \\
\hline 16 & Competências de equilíbrio trabalho/vida pessoal & 12 & 3,1 \\
\hline & & $\mathbf{3 8 3}$ & $\mathbf{1 0 0}$ \\
\hline
\end{tabular}

\section{Competências de Oportunidade}

Quanto às competências de oportunidade, a Tabela 3 aponta que a maior parte dos entrevistados (mais de 2/3 das enunciações) associam o processo de reconhecimento de oportunidades aos seus interesses profissionais. Essa evidência corrobora a percepção de Hills e Laforge (1996) de que esse conceito constitui componente essencial à geração de lucratividade da empresa como mecanismo de sobrevivência e crescimento do negócio. Outros aspectos sinalizados pelos empreendedores que atuam na nova economia são de estarem atentos a espaços de mercado não atendidos e de necessitarem levantar informações de mercado com suporte de capacidades e conhecimentos relacionados ao esforço de marketing, na própria busca de informação sobre posições de mercado, conforme assinalado por Lodish, Morgan e Kallianpur (2002).

Além disso, cabe ressaltar que alguns dos entrevistados reconhecem a sinergia com parceiros como relevante para sua prática empreendedora, que deve ocorre num processo dialógico e reflexivo, de modo a gerar ações com sentido compartilhável no âmbito da rede pessoal que repercute em redes de negócios. 
Portanto, ao ser considerada a limitação na base de recursos, o desenvolvimento de competências que implica a potenciação do diálogo e da reflexão. O aperfeiçoamento dessas capacidades auxilia o empreendedor a perceber e dinamizar as oportunidades que vão emergindo do âmago de sua esfera social (Paiva Jr, 2004).

\section{Tabela 3: Incidência das Competências de Oportunidade}

\begin{tabular}{|c|l|c|c|}
\hline Código & Classificação & Freq. & $\%$ \\
\hline 101 & Identificar as oportunidades de negócios a partir de experiências prévias & 12 & $38,7 \%$ \\
\hline 102 & Avaliar os espaços de mercado não atendidos & 8 & $25,8 \%$ \\
\hline 103 & Pesquisar oportunidades por meio dos esforços de marketing & 7 & $22,6 \%$ \\
\hline 104 & Identificar sinergia com parceiros & 4 & $12,9 \%$ \\
\hline & & $\mathbf{3 1}$ & $\mathbf{1 0 0}$ \\
\hline
\end{tabular}

\section{Competências de Relacionamento}

Analisando-se as competências de relacionamento (Tabela 4), a utilização das redes de relacionamento aparece como sendo mais importante, categorizadas nas relações com parceiros, tanto no sentido de saber utilizarse desses stakeholders, como, sobretudo, na capacidade de negociar com eles de modo a garantir o fortalecimento dos laços de confiança e credibilidade junto a esses interagentes (Brush et al., 2002). Ainda nesta categoria, a descoberta de que recorrem a relações pessoais foi relevante (Minarelli, 2001). $\mathrm{O}$ ato de construir e conservar os relacionamentos com os parceiros, também representativo, está previsto nos estudos de Moger (2000), que denomina tais elementos como ativadores de rede, compreendendo-os como pessoas de habilidades de relacionamento junto a grupos de referência. Esses indivíduos estabelecem relações estratégicas com os clientes, governo, concorrentes, entidades de apoio e demais instituições, buscando compartilhar informações sobre fatos e dinamizar o processo inovador. A competência relacional pode levar o empreendedor a compor articulações de alianças que auxiliam no cumprimento satisfatório dos pactos estratégicos e a propor soluções criativas a baixo custo (Paiva Jr, 2004).

\section{Tabela 4: Incidência das Competências de Relacionamento}

\begin{tabular}{|c|c|c|c|}
\hline Código & Classificação & Freq. & $\%$ \\
\hline 111 & Construir e manter redes de relacionamentos com stakeholders & 9 & 42,9 \\
\hline 112 & Utilizar-se dos relacionamentos & 12 & $\mathbf{5 7 , 1}$ \\
\hline 1121 & Utilizar-se das redes de relacionamentos construídas com stakeholders & (2) & $(9,5)$ \\
\hline 1122 & Negociar com os parceiros de negócios & (6) & $(28,6)$ \\
\hline \multirow[t]{2}{*}{1123} & Recorrer às relações pessoais & (4) & (19) \\
\hline & Total & 21 & 100 \\
\hline
\end{tabular}




\section{Competências Conceituais}

A Tabela 5 demonstra as competências conceituais. A capacidade de inovar, a relação com o risco e a sensibilidade e o desejo de aprender se mostram mais evidentes. A relação com situações de risco, desdobrada na avaliação e no ato de arriscar-se em face de cenários de incerteza, constitui elemento decisivo do ato de empreender, confirmando a posição de autores como Dollinger (1995). A importância dada à aprendizagem demonstra a preocupação do empreendedor que atua na nova economia em estar sempre disposto a aprender, principalmente com suas falhas e insucessos, e compartilhar conhecimentos, fato sinalizado conceitualmente por Kets de Vries (1995). Outra competência relevante foi a de raciocínio de forma criativa, evidenciando a prevalência do pensamento subjetivo no âmbito de reflexão e atuação desses atores. Vários autores (e.g.: Kuratko \& Hodgetts, 1995; Lumpkin \& Dess, 1996, 2001; Man \& Lau, 2000; Morin, 1996) realçam a importância dos componentes da criatividade e independência de pensamento, associando esta característica com a inovação e a autonomia compreendidas como fatores catalisadores de desempenho do empreendedor. Isso ocorre até quando é propiciado ao empreendedor expandir seu estado de reflexão, monitorada pelo compartilhamento de ações com os interagentes da sua rede social. A reflexão auxilia esse ator a dirigir-se no esforço da relacionalidade, de modo a fazer com que dê novo significado continuamente ao seu pensar e agir no plano da interação social (Paiva Jr, 2004).

\section{Tabela 5: Incidência das Competências Conceituais}

\begin{tabular}{|c|l|c|c|}
\hline Código & Classificação & Freq. & $\mathbf{\%}$ \\
\hline $\mathbf{1 2 1}$ & Racionar de forma criativa & $\mathbf{2 0}$ & $\mathbf{1 9 , 9}$ \\
\hline 1211 & Pensar intuitivamente & $(15)$ & $(14,9)$ \\
\hline 1212 & Ver por um ângulo diferente & $(5)$ & $(5)$ \\
\hline $\mathbf{1 2 2}$ & Inovar & $\mathbf{2 4}$ & $\mathbf{2 3 , 8}$ \\
\hline $\mathbf{1 2 3}$ & Lidar com o risco & $\mathbf{2 4}$ & $\mathbf{2 3 , 8}$ \\
\hline 1231 & Avaliar riscos & $(15)$ & $(14,9)$ \\
\hline 1232 & Assumir riscos & $(9)$ & $(8,9)$ \\
\hline $\mathbf{1 2 4}$ & Ter vocação & $\mathbf{3}$ & $\mathbf{3}$ \\
\hline $\mathbf{1 2 5}$ & Ter autonomia & $\mathbf{6}$ & $\mathbf{5 , 9}$ \\
\hline $\mathbf{1 2 6}$ & Ter sensibilidade e vontade de aprender & $\mathbf{2 4}$ & $\mathbf{2 3 , 8}$ \\
\hline & & $\mathbf{1 0 1}$ & $\mathbf{1 0 0}$ \\
\hline
\end{tabular}

\section{Competências Administrativas}

Conforme a Tabela 6 , referente às competências administrativas, evidencia-se uma discussão de reconhecimento do processo organizativo e da liderança como fatores relevantes para o comportamento empreendedor, fato que reafirma a proposição de Birley e Mazuka (2000) quanto ao reconhecimento da capacidade 
de alocação de recursos físicos e dos talentos, como necessários ao crescimento da organização. A liderança assume um papel fundamental, como sugerem Collins e Porras (1997), com perfil mais voltado para a motivação de equipes em termos de afinações, consenso e relacionamento. É surpreendente que o planejamento administrativo não tenha sido destacado, já que é atividade fortemente estimulada entre os empreendedores brasileiros, até mesmo como via de financiamento e viabilização de seus negócios.

\section{Tabela 6: Incidência das Competências Administrativas}

\begin{tabular}{|c|l|c|c|}
\hline Código & Classificação & Freq. & $\mathbf{\%}$ \\
\hline $\mathbf{1 3 1}$ & Planejar & $\mathbf{1}$ & $\mathbf{1 , 1}$ \\
\hline $\mathbf{1 3 2}$ & Organizar & $\mathbf{3 4}$ & $\mathbf{3 7 , 4}$ \\
\hline 1321 & Alocar recursos eficientemente & $(8)$ & $(8,8)$ \\
\hline 1322 & Utilizar recursos e capacidades que gerem resultados & $(24)$ & $(26,4)$ \\
\hline 1323 & Atender de pronto ao cliente & $(1)$ & $(1,1)$ \\
\hline 1324 & Ser ágil em tomada de decisão & $(1)$ & $(1,1)$ \\
\hline $\mathbf{1 3 3}$ & Liderar & $\mathbf{3 4}$ & $\mathbf{3 7 , 4}$ \\
\hline 1331 & Ter liderança sobre a equipe & $(13)$ & $(14,3)$ \\
\hline 1332 & Gerenciar conflitos entre os empregados & $(0)$ & $(0)$ \\
\hline 1333 & Promover o consenso entre os parceiros no processo de tomada de decisão & $(1)$ & $(1,1)$ \\
\hline 1334 & Motivar a equipe & $(15)$ & $(16,5)$ \\
\hline 1335 & Delegar tarefas & $(5)$ & $(5,5)$ \\
\hline $\mathbf{1 3 4}$ & Controlar & $\mathbf{1 1}$ & $\mathbf{1 2 , 1}$ \\
\hline $\mathbf{1 3 5}$ & Atuar mercadologicamente & $\mathbf{1 1}$ & $\mathbf{1 2 , 1}$ \\
\hline 1351 & Comunicar-se eficazmente interna e externamente & $(4)$ & $(4,4)$ \\
\hline 1352 & Expor-se com habilidade junto à mídia & $(1)$ & $(1,1)$ \\
\hline 1353 & Vender eficazmente & $(5)$ & $(5,5)$ \\
\hline 1354 & Atribuir valor ao seu produto/negócio & $(1)$ & $(1,1)$ \\
\hline & & $\mathbf{9 1}$ & $\mathbf{1 0 0}$ \\
\hline
\end{tabular}

\section{Competências Estratégicas}

A Tabela 7, de competências estratégicas, ressalta um relativo equilíbrio entre suas categorias. A administração estratégica, representada pela execução de metas e controle dos resultados das ações estratégicas e pela realização de mudanças em ambientes hostis, demonstra que a compreensão de reviravolta estratégica por meio da análise e reversão de um quadro contingencial desfavorável, assinalado por Mintzberg et al. (2001), tem fundamento junto a este público.

A perspectiva de planejar estrategicamente parece associada ao desenvolvimento de planos de negócios, prática tão destacada nos famigerados estudos de empreendedorismo brasileiros que incentivam a formação empreendedora com base em planos de negócios, a exemplo de Dornelas (2001) e Dolabela (1999). O esforço de posicionamento, por sua vez, confirma a concepção de Lodish et al. (2002) de que a busca de posicionamento representa uma interface valiosa de empreendedorismo e marketing e repercute na exploração de novas oportunidades. 


\section{Tabela 7: Incidência das Competências Estratégicas}

\begin{tabular}{|c|l|c|c|}
\hline Código & Classificação & Freq. & $\mathbf{\%}$ \\
\hline $\mathbf{1 4 1}$ & Planejar estrategicamente & $\mathbf{2 1}$ & $\mathbf{3 4 , 4}$ \\
\hline 1411 & Ter visão abrangente & $(7)$ & $(11,5)$ \\
\hline 1412 & Estabelecer e avaliar objetivos & $(3)$ & $(4,9)$ \\
\hline 1413 & Ter intencionalidade para a ação & $(11)$ & $(18)$ \\
\hline $\mathbf{1 4 2}$ & Posicionar o negócio/produto no mercado & $\mathbf{1 7}$ & $\mathbf{2 7 , 8}$ \\
\hline 1421 & Definir e avaliar posicionamento & $(2)$ & $(3,3)$ \\
\hline 1422 & Estabelecer o posicionamento & $(3)$ & $(4,9)$ \\
\hline 1423 & Gerar uma identidade corporativa a partir de suas características & $(1)$ & $(1,6)$ \\
\hline 1424 & Ter agressividade competitiva & $(11)$ & $(18)$ \\
\hline $\mathbf{1 4 3}$ & Gerir estrategicamente & $\mathbf{2 3}$ & $\mathbf{3 7 , 7}$ \\
\hline 1431 & Realizar mudanças estratégicas em ambientes adversos & $(8)$ & $(13,1)$ \\
\hline 1432 & Executar metas estabelecidas & $(10)$ & $(16,4)$ \\
\hline 1433 & Utilizar táticas & $(4)$ & $(6,6)$ \\
\hline 1434 & Orçar a implementação da estratégia & $(0)$ & $(0)$ \\
\hline 1435 & Controlar os resultados das estratégias & $(1)$ & $(1,6)$ \\
\hline & & $\mathbf{6 1}$ & $\mathbf{1 0 0}$ \\
\hline
\end{tabular}

\section{Competências de Comprometimento}

Mais uma área de competências que demonstra equilíbrio entre suas categorias. A Tabela 8, das competências de comprometimento, demonstra que o empreendedor tem compromisso com o negócio em proporção semelhante aos seus compromissos pessoais, como se o dirigente e sua organização fossem um mesmo organismo. Tal constatação confirma o estudo de Kuratko e Hodgetts (1995); eles asseveram que as intenções, sentimentos, desejos e motivações pessoais do empreendedor, vinculados à sua necessidade de expansão e manutenção do negócio, são essenciais para o benefício da organização.

\section{Tabela 8: Incidência das Competências de Comprometimento}

\begin{tabular}{|c|c|c|c|}
\hline Código & Classificação & Freq. & $\%$ \\
\hline 151 & Comprometimento com o negócio & 31 & 47 \\
\hline 1511 & Manter o comprometimento em relação ao negócio & (12) & $(18,2)$ \\
\hline 1512 & Comprometer-se com os objetivos de longo prazo & (2) & (3) \\
\hline 1513 & Dedicar-se ao trabalho & (13) & $(19,7)$ \\
\hline 1514 & Comprometer-se com a equipe & (4) & $(6,1)$ \\
\hline 152 & Comprometimento pessoal & 35 & 53 \\
\hline 1521 & Comprometer-se com suas crenças e valores & (12) & $(18,2)$ \\
\hline 1522 & Comprometer-se com objetivos pessoais & (15) & $(22,7)$ \\
\hline \multirow[t]{2}{*}{1523} & Recomeçar após fracassos & (8) & $(12,1)$ \\
\hline & Total & 66 & 100 \\
\hline
\end{tabular}




\section{Competências de Equilíbrio Trabalho/Vida Pessoal}

Ao observar a existência de fatores do cotidiano, que representam fontes de estresse para o empreendedor, num estudo realizado no começo dos anos 80, Boyd e Gumpert (1983) já associam tal questão ao risco assumido nos estágios de criação e expansão do negócio, à falta de recursos para satisfazer a necessidade de realização, à imersão na atividade, que provoca o isolamento social, e aos problemas circunstanciais do dia-a-dia.

As saídas de equilíbrio propostas pelos autores apontam o envolvimento com redes de dirigentes de empresas, intervalos de férias ou feriados curtos ou longos que permitam a auto-renovação e abertura de veias de comunicação com as equipes de modo a torná-las mais produtivas e garantir a delegação de tarefas, além da busca de satisfação em atividades sociais e recreativas, alheias à rotina da empresa.

\section{Tabela 9: Incidência das Competências de Equilíbrio Trabalho/Vida Pessoal}

\begin{tabular}{|c|c|c|c|}
\hline Código & Classificação & Freq. & Part. \\
\hline 161 & Dar vazão ao estresse & 8 & $66,6 \%$ \\
\hline 162 & Ter uma compreensão lúdica/prazerosa do trabalho & 4 & $33,3 \%$ \\
\hline & Total & 12 & $100 \%$ \\
\hline
\end{tabular}

\section{CONCLUSÕES E IMPLICAÇÕES}

Com base nas questões norteadoras deste estudo, podemos elaborar nossas conclusões, bem como analisar algumas implicações. Em relação à primeira pergunta, Que comportamentos específicos compõem as áreas de competências empreendedoras?, nosso estudo apontou que, das sete áreas de competência identificadas nesta pesquisa, 50 comportamentos específicos emergiram. Dentre eles, alguns merecem destaque, por terem sido os mais representativos neste estudo. Considerando-se as competências conceituais dos empreendedores, podemos destacar a sensibilidade e a vontade de aprender como expressão do aprender a aprender, essenciais ao processo de desenvolvimento de competências; o pensar intuitivamente, marcante na ação independente e criativa do sujeito da ação empreendedora; e a facilidade de avaliar riscos em meio a cenários caóticos e de incerteza.

Quanto às competências administrativas, merecem destaque a utilização de recursos e de capacidades que repercutam na geração de resultados eficazes e a 
motivação da equipe de colaboradores internos. Estes aspectos compreendem capacidades realçadas nos conglomerados dos relatos como significativas e dignas de consideração científica. Finalmente, o comprometimento com os objetivos pessoais sobressaem no conjunto de compromissos relatados nas entrevistas, que também merecem discussões mais exaustivas no bojo dos estudos de empreendedorismo.

Quanto à segunda pergunta, Que áreas de competências empreendedoras são mais relevantes nos comportamentos de dirigentes de perfil empreendedor?, o desafio deste estudo consistiu em apresentar os resultados de áreas de competências empreendedoras de dirigentes de empresas que atuam em serviços na nova economia os quais demonstram que os estoques de competências específicas acumuladas pelos dirigentes estão no saber fazer e no saber ser, que são peculiares à prática empreendedora. Esta concepção é ilustrada pela prevalência das competências conceituais, até mesmo de teor subjetivo, e pelas competências administrativas, voltadas para a otimização dos recursos físicos, tecnológicos e junto aos colaboradores internos e parceiros, de modo a alcançar resultados satisfatórios.

Como descoberta do estudo, vale destacar a competência de equilíbrio entre a dinâmica de trabalho e as demandas do cotidiano do dirigente, que o inspiram a buscar escapes da exaustão física e psicológica, ameaçadores de seu rendimento nas atividades empresariais, o que repercute na tentativa de encontrar fórmulas de saídas criativas e lúdicas para garantir um contínuo estado de revigoramento pessoal e profissional.

O planejamento formal parece ser uma atividade alheia às práticas administrativas do dia-a-dia do dirigente de perfil empreendedor. Este achado denota que a elaboração de um eventual plano de negócio tem validade tão somente no estágio de abertura da empresa, à parte do manuseio e revisão ao longo das etapas subseqüentes do ciclo de vida organizacional.

Para que se desenvolva a competência empreendedora se faz necessária a abertura para dimensões multidisciplinares estruturadas com base em anel transversal de conhecimento, erigido sob a marca de reflexões, num âmbito do saber ser, da práxis e das relações. A expansão dessas competências é delineada por fatores-chaves de desenvolvimento de confiança na rede social do empreendedor que redunda na escolha de ações dotadas de sentido compartilhável entre seus parceiros de negócios. Esse fato envolve a busca de investimentos deliberados em formação de expertises centradas na dinamização de alianças empreendedoras de geração e desenvolvimento de valor cultural, político e socioeconômico que beneficie tanto os interagentes da rede, como o conjunto da sociedade. 
Em meio à limitação na base de recursos, o desenvolvimento de competências favorecedoras do diálogo e da reflexão conduz o empreendedor a lograr êxito nas articulações que conduzem ao cumprimento satisfatório das exigências de pactos e na proposição de soluções inovadoras de baixo custo. O estilo diferenciado de gestão permeado pelo confiar e pelo aprender, em meio a situações de caos, fica potenciado por essas linhas de competências que minoram as condições de insegurança no âmbito das transações e contempla combinações de alianças empreendedoras de gênero perene promissor.

\section{Limitações e Recomendações para Futuras Pesquisas}

Embora considerando a representatividade empresarial do eixo Rio-São Paulo como regiões emergentes de práticas empresariais no âmbito nacional e internacional, o estudo limita-se à configuração de um horizonte amostral de sete dirigentes de empresas. E, portanto, sugere a continuação junto a mais empresários e intraempreendedores, até mesmo expandindo o espectro para outras localidades do país. Outra limitação metodológica residiu na pesquisa qualitativa básica, com uso da técnica de análise de conteúdo e demandando uma apreciação epistemológica rigorosa com uso de mecanismos de triangulação de dados, por meio de uma análise de discurso ou análise narrativa para compreensão da atmosfera contextual que permeia a identificação das competências do sujeito empreendedor.

\section{Artigo recebido em 14.05.2004. Aprovado em 03.09.2004.}

\section{Agradecimentos}

Os realizadores desta pesquisa agradecem o apoio da CAPES e do CNPq.

\section{ReferênCIAS BibliográficAs}

Bardin, L. (1977). Análise de Conteúdo. Lisboa: Edições 70.

Bauer, M. W., \&

Gaskell, G. (2002). Pesquisa qualitativa com texto, imagem e som: um manual prático. Petrópolis: Vozes.

Benko, G. (2002).

Economia, espaço e globalização: na aurora do século XXI (3a ed.). São Paulo: Hucitec. 
Birley, S., \&

Muzyka, D. F. (2001).

Dominando os desafios do empreendedor. São Paulo: Makron Books.

Boyd, P. \&

Gumpert, D. E. (1992).

Coping with entrepreneurial stress. Leadership and organization development Journal, 13(2), 27-32.

Brush, C. G.,

Greene, P. G., \&

Hart, M. M. (2002, janeiro/março).

Empreendedorismo e construção da base de recursos. Revista de Administração de Empresas, 42(1), 20-35.

Collins, J., \&

Porras, J. (1997).

Feitas para durar (7a ed.). São Paulo: Rocco.

Coriat, B. (1994).

Pensar pelo avesso: o modelo japonês de trabalho e organização. Rio de Janeiro: Revan/UFRJ.

Castells, M. (1999).

A sociedade em rede: a era da informação: economia, sociedade $e$ cultura (5a ed.). São Paulo: Paz e Terra.

Demo, P. (1994).

O futuro do trabalhador do futuro: ótica estratégica do desenvolvimento humano. Genebra: OIT.

Dollinger, M. J. (1995).

Entrepreneurship: strategies and resources. Illinois: Irwin.
Dolabela, F. (1999).

O segredo de Luísa. São Paulo:

Cultura Editores Associados.

Dornelas, J. C. A. (2001).

Empreendedorismo: transformando idéias em negócios. Rio de Janeiro: Campus.

Drucker, P. (2002).

Sociedade pós-capitalista. São

Paulo: Pioneira.

Enriquez, E. (1997, Janeiro/Março).

$\mathrm{O}$ indivíduo preso na armadilha da estrutura estratégica. Revista de Administração de Empresa, 37(1), 1829.

Fraser, P. (2000, Fall).

Insight or enigma? Marketing, entrepreneurship and complexity science. Journal of Research in Marketing \& Entrepreneurship, 2(3), 249-257.

Friedman, S.,

Christesen, P., \&

Degroot, J. (1998, November/December). Work and life balance: the end of the zero-sum game. Harvard Business Review, 76(6), 119-129.

Gibb, A. (1999, Summer).

Can we buid 'efective' entrepreneurship through management development? Journal of General Management, 24(4), 1-22.

Hills, G., \&

Laforge, R. W. (1996).

Marketing and entrepreneurship.

Chicago: University of Illinois. 
Kerns, C. D. (2002, July/August).

An entrepreneurial approach to strategic direction setting. Business Horizons, 45(4), 2-6.

Keegan, W. J. (1995).

Global Marketing Management (5a ed.). New Jersey: Prentice-Hall.

Kets De Vries, M. F. R. (1995).

Organizational paradoxes: clinical approaches to management ( $2 \mathrm{a}$ ed.). Londres: Routledge.

Kuratko, D. F., \&

Hodgetts, R. M. (1995).

Entrepreneurship: a contemporary approach (3a ed.). Fort Worth: Dryden Press.

Lodish, L.;

Morgan, H. L., \&

Kallianpur,A. (2002).

Empreendedorismo e marketing: lições do curso de MBA da Wharton School. Rio de Janeiro: Campus.

Lumpkin, G. T., \&

Dess, G. G. (1996, January).

Clarifying the entrepreneurial orientation construct and linking it to performance. Academy of Management Review, 21(1), 135-172.

Man, T. W. Y., \&

Lau, T. (2000, September).

Entrepreneurial competencies of SME owner/manager in the Hong Kong services sector: a qualitative analysis. Journal of Enterprising Culture, 8 (3), 235-254.

Man, T. W. Y.,

Lau, T., \&

Chan, K. F. (2002, March).

The competitiveness of small and medium entreprises: a conceptualization with focus on entrepreneurial competencies. Journal of Business Venturing, 17(2), 123-142.

Miles, M. B., \&

Huberman, A. M. (1994).

Qualitative data analysis: an expanded sourcebook. Thousand Oaks: Sage.

Minarelli, J. A. (2001).

Networking (3a ed) São Paulo: Gente.

Mintzberg, H.,

Ahlstrand, B., \&

Lampel, J. (2000).

Safári de estratégia: um roteiro pela selva do planejamento estratégico. Porto Alegre: Bookman.

Mintzberg, H., \&

Quinn, J. B. (2001).

$O$ processo da estratégia ( $2 \mathrm{a}$ ed). Porto Alegre: Bookman.

Moger, S. (2000).

Enhancing the marketing/ entrepreneurship interface in SMEs the contibution of metwork activation. Anais do Encontro de estudos sobre empreendedorismo e gestão de pequenas empresas, Maringá, $\mathrm{PR}, 1$.

Morin, E. (1996).

A noção de sujeito. In D. F. Schinitman (Org.). Novos paradigmas, cultura e subjetividade. Porto Alegre: Artes Médicas. 
Paiva, F. G., Jr. (2004).

O empreendedorismo na ação de empreender: uma análise sob o enfoque da fenomenologia sociológica de Alfred Schütz. Tese de doutorado. Centro de Pós-graduação e Pesquisas em Administração, Universidade Federal de Minas Gerais. Minas Gerais, Brasil.

Pinto, L. F. S. (2000).

O espírito empreendedor no processo estratégico. Conjuntura Econômica, 54(12), 61-63.

Ring, P. S., \&

Van De Ven, A. H. (1994, January).

Developmental processes of cooperative interorganizational relationships. Academy of Management Review, 19(1), 90-118.
Schön, D. (1983).

The reflexive practitioner: how professionals think in action. New York: Basic Books.

Stevenson, H. H., \&

Gumpert, D. E. (1985, March/April).

The heart of entrepreneurship. Harvard Business Review, 63(2), 8594.

Storey, D. J. (2002, August).

Education, training and development policies and practicies in médiumsized companies in the UK: do they really influence firm performance? Omega, 30 (4), 249-264. 


\section{APÊNDICE}

\section{Tabela 10: Destaque de Trechos-chave na Caracterização dos Códigos}

\begin{tabular}{|c|c|c|}
\hline Cód. & [Ref. (entrevistado/citação)]/Trecho representativo de cada código & Freq. \\
\hline 101 & 7(302). Víamos oportunidades ilimitadas em várias áreas. & 12 \\
\hline 102 & 2(63). Vejo a figura do empreendedor (...) descobre a oportunidade onde ninguém viu. & 8 \\
\hline 103 & 3(118). E saíamos à caça das informações (...). & 7 \\
\hline 104 & 7(309). Isso nos levou a combinar os talentos e as qualidades. & 4 \\
\hline 111 & 3(125). Com as pessoas (...) sempre tive uma regra: transparência total. & 9 \\
\hline 1121 & 3(126). (...) antes de tomar a decisão, discutir (...). & 2 \\
\hline 1122 & 4(197). Fizemos acordos vantajosos (...). & 6 \\
\hline 1123 & 5(258). O negócio da honestidade é do meu pai (...). & 4 \\
\hline 1211 & 6(268). Não foi uma oportunidade cientificamente pesquisada. & 15 \\
\hline 1212 & 3(148). A capacidade de ver coisas que as pessoas em geral não conseguem ver. & 5 \\
\hline 122 & 4(218). Tínhamos acabado de inventar a solução (...). & 31 \\
\hline 1231 & 1(55). Tem que olhar para o caixa da empresa (...). & 15 \\
\hline 1232 & 6(280). Nenhuma pessoa normal faria isso. & 9 \\
\hline 124 & 5(227). Talvez seja DNA. & 3 \\
\hline 125 & 5(240) Nunca mais vou ser empregado de ninguém. & 6 \\
\hline 126 & 2(66). O sucesso (...) conseqüência de experiências bem sucedidas (...) & 24 \\
\hline 131 & 4(215). (...) passamos por reuniões nas quais discutimos o fechamento da empresa. & 1 \\
\hline 1321 & 7(314). Peguei duas pessoas e organizei um modelinho de gestão (...). & 8 \\
\hline 1322 & 5(247). E aí passamos a investir mais em tecnologia (...). & 24 \\
\hline 1323 & 4(172). As pessoas (...) mandavam e-mails, pediam para incluir coisas (...). & 1 \\
\hline 1324 & 4(169). Já na terceira semana, registrei o nome (...). & 1 \\
\hline 1331 & 1(26). (...) o bom empreendedor (...) tem que transmitir as idéias sem dizer nada. & 13 \\
\hline 1332 & & 0 \\
\hline 1333 & 3(133). Se não for aprovada, me declaro voto vencido e sigo a decisão. & 1 \\
\hline 1334 & 1(25). (...) idéia por conta própria (...) a idéia sendo dele, sua motivação é maior. & 15 \\
\hline 1335 & 1(52). (...) se cercar de pessoas que saibam gerir processos (...). & 5 \\
\hline 134 & 4(185). As pessoas ganhavam bônus de desempenho em função das metas (...) & 11 \\
\hline 1351 & 1(49). Nosso cartão (...) vai com slogan e tudo. & 4 \\
\hline 1352 & 4(206). A mídia dava atenção. & 1 \\
\hline 1353 & $\begin{array}{l}5(231) .(\ldots) \text { tarefa insana de convencer clientes }(\ldots) \text { que era possível trabalhar pela Internet } \\
\text { (...) comprando (...) geograficamente em outro lugar. }\end{array}$ & 5 \\
\hline 1354 & 4(213). Se você não valorizar (...). & 1 \\
\hline 1411 & 3(136). (...) mais importante do que ler é saber ler. & 7 \\
\hline 1412 & 7(312). (...) voltei com uma idéia fixa: ganhar dinheiro. & 3 \\
\hline 1413 & 2(64). (...) a necessidade de fazer algo. & 11 \\
\hline 1421 & $3(142)$. (...) que tenha foco. & 2 \\
\hline 1422 & 1(34). (...) essa força para tornar algo conhecido. & 3 \\
\hline 1423 & 1(51). (...) a sua empresa tem que ter a sua identidade. & 1 \\
\hline 1424 & 4(187). Éramos muito pequenos, mas enfrentávamos o gigante na cara-de-pau. & 11 \\
\hline 1431 & 2(93). (...) foi preciso rever o plano. & 8 \\
\hline 1432 & 3(124). Até agora todas as minhas metas foram cumpridas. & 10 \\
\hline 1433 & 1(29). (...) acaba usando técnicas de guerrilha. & 4 \\
\hline 1434 & & 0 \\
\hline 1435 & 7(318). Implementamos (...) por que ela faz? (...) não tem caixa? (...). & 1 \\
\hline 1511 & 6(285). (...) ter uma fidelidade muito grande à idéia original. & 12 \\
\hline 1512 & 1(23). Daqui a um ano, saberemos como ficará a empresa. & 2 \\
\hline 1513 & 1(30). Não tem fim de semana (...). & 13 \\
\hline 1514 & 3(153). As pessoas precisam estar felizes com aquele projeto. & 4 \\
\hline 1521 & 3(120). (...) construir alguma coisa que tenha algum sentido para a vida (...). & 12 \\
\hline 1522 & 4(156). Tina desejos (...) de abrir sua própria empresa. & 15 \\
\hline 1523 & 7(306). Estivemos quebrados duas vezes. & 8 \\
\hline 161 & 2(86). Eu leio (...) durmo (...) faço ginástica. & 8 \\
\hline 162 & 4(208). Mas não era um sacrifício extremo, tinha prazer também. & 4 \\
\hline
\end{tabular}

